\title{
Antixenosis and antibiosis effects of Oryza nivara accessions harbouring bph2 gene on brown planthopper [Nilaparvata lugens (Stal)]
}

\author{
S.A.P. Madurangi ${ }^{1}$, Disna Ratnasekera ${ }^{1}$, S.G.J.N. Senanayake ${ }^{1 *}$, W.L.G. Samarasinghe ${ }^{2}$ and \\ P.V. Hemachandra ${ }^{2}$ \\ ${ }^{I}$ Department of Agricultural Biology, Faculty of Agriculture, University of Ruhuna, Mapalana, Kamburupitiya. \\ ${ }^{2}$ Rice Research and Development Institute, Bathalagoda, Ibbagamuwa.
}

Revised: 05 February 2013; Accepted: 13 March 2013

\begin{abstract}
Gene bph2 is one of the 21 brown planthopper (BPH), Nilaparvata lugens (Stal) resistant genes identified so far in several indica cultivars and wild relatives. The present study evaluated Oryza nivara accessions collected from different locations in Sri Lanka for bph2 and, antibiosis and antixenosis effects of $O$. nivara accessions harbouring bph2 gene on BPH. The five O. nivara accessions; WRAC 02, WRAC 04, WRAC 07, WRAC 21 and WRAC 25 amplified the resistant band (300 bp) indicating the presence of the bph2 gene in their genomes. The level of resistance observed in these accessions was high and showed negative effects on honeydew production and nymphal survival (antibiosis) and revealed antixenosis action against nymphs and oviposition. In addition, dynamic response mechanisms of $\mathrm{BPH}$ against $O$. nivara accessions that possess bph2 was found, which may be indicative of the complex structure of genetics of resistance of these accessions. Substantial level of resistance similar to that in Ptb 33, observed in $O$. nivara accessions WRAC 02, WRAC 04 gives a clue to the possible existence of polygenic resistance as detected in Ptb 33. Results of this study highlighted the possibility of the use of $O$. nivara accessions that possess bph2 gene in their genome as a potential source of resistance in pyramiding of genes for $\mathrm{BPH}$ resistance to avoid the genetic uniformity of $\mathrm{BPH}$ resistant rice varieties cultivated in Sri Lanka in the future.
\end{abstract}

Keywords: Antibiosis, antixenosis, bph2, brown planthopper, Oryza nivara.

\section{INTRODUCTION}

The brown planthopper (BPH), Nilaparvata lugens (Stal) (Homoptera: Delphacidae) is one of the most destructive monophagous insect pests of rice throughout the rice growing countries in Asia. The $\mathrm{BPH}$ damages the rice plant directly by sucking the phloem sap and plugging the xylem and phloem with their feeding sheaths, which causes serious yield reductions (Sogawa \& Cheng, 1977). $\mathrm{BPH}$ also serves as a vector for transmission of viruses that cause grassy stunt (Rivera et al., 1966) and ragged stunt (Ling et al., 1978) viral diseases in rice. Heavy dependence on chemical pesticides for the control of this pest leads to many adverse effects like harmful effects on natural enemies, development of resistant biotypes, environmental pollution and high cost of production (Kudagamage \& Nugaliyadda, 1995). It has been reported that host plant resistance is the most economic, least complicated and environmentally friendly approach for protecting crops against insect pest damage (Pathak \& Kush, 1979).

The presence of host plant resistance against BPH in rice was first reported by Pathak et al. (1969). It has been reported that the resistant varieties suppressed the weight gain of nymphs and maintained low BPH populations across multiple generations in a large production area (Cohen et al., 1997; Jung \& Im, 2005). Therefore, the use of varietal resistance to manage this pest is considered as an important approach in integrated pest management. In general, resistant rice plants exhibit two strategies against BPH: antixenosis and antibiosis. Antixenosis affects insect settling, colonization or oviposition and antibiosis reduces insect feeding, growth rate or survival (Alarn \& Cohen, 1998).

According to Rahman et al. (2009), 21 BPH resistant genes have already been identified and characterized in

\footnotetext{
"Corresponding author (gmnsenanayake@yahoo.com)
} 
traditional rice cultivars and wild rice species. Out of 22 wild rice species, $\mathrm{BPH}$ resistance has been detected only in a few species, i.e. O. officinalis (Hirabayashi et al., 1998), O. australiensis (Ishii et al., 1994), O. eichingeri (Liu et al., 2001), O. minuta (Rahman et al., 2009) and O. latifolia (Yang et al., 2002). However, due to undesirable agro-morphological traits associated with the $\mathrm{BPH}$ resistance in these wild relatives, transferring the resistance to high yielding varieties through conventional breeding techniques is not easy.

Out of the five wild relatives of rice, $O$. nivara is the most common and widely distributed species found in Sri Lanka (Hemachandra et al., 2010a). In a previous study (Madurangi et al., 2011) it was reported that the high level of resistance observed in O. nivara accession (WRAC 04) collected from Otththapahuwa in the Anuradhapura District is mainly due to the presence of the bph2 gene in its genome. WRAC 04 accession has been already used to develop BPH resistant lines (Hemachandra et al., 2010b) at the Rice Research and Development Institute (RRDI), Bathalagoda. The results of wide hybridization tests have proved that it can be incorporated into O. sativa. Lines derived from the cross between WRAC 04 (male parent) and Bg 380 (female parent-susceptible check) were resistant to BPH populations available in Sri Lanka (Hemachandra et al., 2010b). These findings highlight the importance of screening the available $O$. nivara germplasm with a similar genome to the cultivated rice, $O$. sativa against $\mathrm{BPH}$ resistance in order to identify potential donors towards developing rice varieties having broadbased and durable resistance to $\mathrm{BPH}$.

Gene bph2 is one of the $21 \mathrm{BPH}$ resistant genes identified so far in several indica cultivars. It was originally identified as a recessive gene in an indica breeding line, Karsamba Red ADS7 (Athwal et al., 1971) and mapped on the long arm of chromosome 12 (Murata et al., 1998). Khush (1979) reported that the high level of resistance observed in Ptb 33 was due to the combination of two different resistant genes, bph2 and Bph3.

The introduction of varietal resistance to manage the BPH problem in Sri Lanka commenced with the recommendation of the first resistant variety, Bg 379/2 (variety developed using Ptb 33) in 1980 (Kudagamage $\&$ Nugaliyadda, 1982). Since then, several resistant donors have been used in developing $\mathrm{BPH}$ resistant rice varieties. However, only the resistance of Ptb 33 has been successfully incorporated into high yielding varieties (Kudagamage \& Nugaliyadda, 1995) and as such bph2 and Bph3 genes play a major role in $\mathrm{BPH}$ management in Sri Lanka.
For incorporation of $O$. nivara in the rice improvement programme, it is essential to evaluate its resistance level and illustrate the biological effects, i.e. antibiosis and antixenosis on BPH. Therefore, the present study was aimed at screening the $O$. nivara genome against KAM 4 primer to detect the accessions harbouring bph2 gene and to illustrate the antibiosis and antixenosis effects of positive accessions on $\mathrm{BPH}$, in order to assess the potential for using them in rice varietal improvement (gene pyramiding) in Sri Lanka.

\section{METHODS AND MATERIALS}

Seventeen $O$. nivara accessions collected from different locations in Sri Lanka and maintained by RRDI, Bathalagoda, and check varieties; Ptb 33 (resistant check), Bg 380 (susceptible check) and Bg 379/2 (moderately resistant check) were used for the molecular study (Table 1). Accessions selected from the molecular screening were used in the bioassay tests. The BPH culture maintained at RRDI, Bathalagoda on susceptible rice

Table 1: Details of $O$. nivara accessions used in the study

\begin{tabular}{|c|c|c|c|}
\hline No. & Accession No. & Collected location & District \\
\hline 1 & WRAC 01 & Bulunawewa & Matale \\
\hline 2 & WRAC 02 & Pelbediyawa & Matale \\
\hline 3 & WRAC 04 & Otththapahuwa & Anuradhapura \\
\hline 4 & WRAC 07 & Ilakkttuwa & Puttlam \\
\hline 5 & WRAC 11 & $\begin{array}{l}\text { Kabaraya wewa, } \\
\text { Poonewa }\end{array}$ & Anuradhapura \\
\hline 6 & WRAC 12 & Sangilikulama wewa & Anuradhapura \\
\hline 7 & WRAC 14 & Yakadapotha & Kurunegala \\
\hline 8 & WRAC 19 & Ihalawewa & Anuradhapura \\
\hline 9 & WRAC 21 & Inamaluwa & Matale \\
\hline 10 & WRAC 22 & Rangirigama & Matale \\
\hline 11 & WRAC 24 & A-9 road $105 \mathrm{~km}$ post & Anuradhapura \\
\hline 12 & WRAC 25 & A-9 road $105 \mathrm{~km}$ post & Anuradhapura \\
\hline 13 & WRAC 35 & Olugaskade tank & Anuradhapura \\
\hline 14 & WRAC 41 & Paranagama & Matale \\
\hline 15 & WRAC 46 & Mahiyanganaya & Badulla \\
\hline 16 & WRAC 62 & $\begin{array}{l}\text { Meegahawewa, } \\
\text { Weerawewa }\end{array}$ & Anuradhapura \\
\hline 17 & 9864 & Matara & Matara \\
\hline
\end{tabular}


variety $\mathrm{Bg} 380$ for many years and subsequently cultured on Bg 380 for a year in a planthouse at the Department of Agricultural Biology, Faculty of Agriculture, University of Ruhuna was used for the bioassay tests.

\section{Molecular screening}

DNA was extracted from healthy tender leaves of test accessions and varieties using the protocol described by Anushka et al. (2008). The DNA extracted from test plants were screened for the presence or absence of the bph2 gene by PCR amplification using the STS marker, KAM 4 (F- 5' TAACTGGTGTTAGTGCGAATGC 3', R- 5' AATTCACGGCATGTGAAGCCCTAG 3'), which shows complete co-segregation with bph2.

PCR was performed following the procedure described by Murai et al. (2001). The PCR mixture contained 50-100 ng template DNA, 10 pmol of each primers, $0.2 \mathrm{mM}$ dNTP's each, $1 \mathrm{X}$ buffer $(20 \mathrm{mM}$ Tris $\mathrm{pH} 8.0$ including $2.5 \mathrm{mM} \mathrm{MgCl}$ ) and 0.2 units of Taq polymerase in a total volume of $15 \mu \mathrm{L}$. PCR was performed using Master Cycler Gradient. PCR mixtures were initially denatured at $94{ }^{\circ} \mathrm{C}$ for $5 \mathrm{~min}$ followed by 30 cycles of PCR amplification using the following parameters: denaturation of $94^{\circ} \mathrm{C}(30 \mathrm{~s})$, primer annealing at $66{ }^{\circ} \mathrm{C}(1 \mathrm{~min})$ and primer extension at $72{ }^{\circ} \mathrm{C}(1 \mathrm{~min})$ with final extension at $72{ }^{\circ} \mathrm{C}$ for $10 \mathrm{~min}$. PCR products were electrophoresed in $1.4 \%$ agarose gel to separate the DNA fragments. The gel was subsequently stained by ethidium bromide and the amplified DNA fragments were visualized under UV light. The screening was repeated twice.

\section{BPH bioassays}

\section{Evaluation of $B P H$ resistance of $O$. nivara accessions}

Evaluation of $\mathrm{BPH}$ resistance of test plants was performed following the conventional seed box test described by Heinrichs et al. (1985). O. nivara accessions selected through molecular screening (harbouring bph2 gene) and the check varieties were sown in a galvanized tray $(60 \times 40 \times 10 \mathrm{~cm})$ filled with sterilized soil up to a depth of $5 \mathrm{~cm}$. The seeds were sown in $40 \mathrm{~cm}$ long-rows and spaced $5 \mathrm{~cm}$ between the rows. When the seedlings were $7 \mathrm{~d}$ old (at 3 leaf stage), they were infested with $2^{\text {nd }}$ instar nymphs of BPH at the rate of 3 nymphs/seedling. The test was carried out with 4 replicates in a completely randomized design (CRD). The standard evaluation system for rice, developed by the International Rice Research Institute (IRRI), Laguna, Philippines in 1988 was used to score the BPH damage. Accordingly BPH damage was rated by a 0 to 9 scale. The damage score was recorded when about $90 \%$ of the susceptible check (Bg 380 ) seedlings were dead. The screening was repeated twice.

\section{Antixenosis resistance}

Estimation of non preference of BPH nymphs to settle on test seedlings: Antixenosis of $O$. nivara accessions carrying the bph2 gene against settling of BPH nymphs was assessed using conventional seed box test described by Heinrichs et al. (1985). Ten days after sowing of selected accessions, approximately 250 second instar BPH nymphs were released on to the seedlings. The number of nymphs on each seedling was counted at 12 , 24, 48 and $72 \mathrm{~h}$ after infestation. The seedlings were disturbed after each count for re-orientation of nymphs on seedlings. Evaluation was performed following CRD with 4 replicates and repeated twice.

Oviposition: Antixenosis of test plants against oviposition was assessed by the procedure described using Heinrichs et al. (1985). Single seedlings from 6 rice accessions were transplanted in a circular fashion about $2-3 \mathrm{~cm}$ from the edge of $20 \mathrm{~cm}$ clay pots as shown in Table 2 . To create free choice conditions, 3 check varieties, namely Ptb 33, Bg 379/2 and $\mathrm{Bg} 380$, were included in each arrangement while the $O$. nivara accessions were selected randomly for the test with the accessions that showed positive results for the bph2 gene. Five week-old plants were prepared for the test by removing all leaves while keeping the stem part up to $20-25 \mathrm{~cm}$ height. Plants were then infested with 10 gravid brachypterous BPH females and covered using mylar cages. The insects were allowed to oviposit on any variety they chose for $48 \mathrm{~h}$ and subsequently removed from the plants. Leaf sheaths of tested accessions were observed for determination of the

Table 2: Planting arrangement of test plants for oviposition assessment

\begin{tabular}{cl}
\hline Arrangement No. & Test plants \\
\hline 1 & Ptb 33, WRAC 01, Bg 380, WRAC 21, \\
& Bg 379/2, 9864 \\
\hline 2 & Ptb 33, WRAC 35, Bg 380,WRAC 22, \\
& Bg 379/2, WRAC 25 \\
\hline 3 & Ptb 33, WRAC 24, Bg 380, WRAC 14, \\
& Bg 379/2, WRAC 07 \\
\hline 4 & Ptb 33, WRAC 12, Bg 380, WRAC 02, \\
& Bg 379/2, WRAC 04 \\
\hline
\end{tabular}


number of eggs laid in each accession by observing under the light microscope $(10 \times 5)$. Preference for egg laying was assessed by following CRD and each arrangement was replicated 4 times and repeated twice.

\section{Antibiosis resistance}

Evaluation of resistance to feeding by $\mathrm{BPH}$ : Reaction of BPH to host plants and the plant resistance to feeding by BPH were determined based on honeydew production. The $O$. nivara accessions with bph 2 and the check varieties were grown singly in $15 \mathrm{~cm}$ clay pots and managed free of BPH infestations. Screening for resistance was performed when they reached the age of two months. A Whatman no. 2 filter paper stained with the pigment bromocresol green $(2 \mathrm{mg} / 1 \mathrm{~mL}$ of $70 \%$ ethanol) was placed around the base of the feeding chamber before infesting with BPH. A pair of BPH females previously starved for $4 \mathrm{~h}$ were placed in the feeding chamber and allowed to feed for $24 \mathrm{~h}$. Honeydew excreted by BPH was absorbed by the filter paper and appeared as a blue spot. Area of the spot was proportional to the honeydew production and therefore to the amount of $\mathrm{BPH}$ feeding (Heinrichs et al., 1985). Screening was conducted following the randomized complete block design (RCBD) with 4 replicates and was repeated twice.

\section{Evaluation of survival of nymphs on test accessions}

Ten-day old seedlings of the test accessions were placed singly in test tubes (diameter $=2 \mathrm{~cm}$ ) containing distilled water and each seedling was infested with 10 newly emerged first instar BPH nymphs. The test tubes were loosely plugged with cotton wool to prevent the insects from escaping. The seedling host was changed every $2 \mathrm{~d}$ and a count on the number of nymphs surviving was recorded until they became adults. Antibiosis in terms of nymphs survived on test accessions was measured following the CRD with 4 replicates and repeated twice.

\section{Statistical analysis}

Data were subjected to analysis of variance (ANOVA) and means were separated by Duncan multiple range test (DMRT) using SAS 6.12 version (SAS Institute, 1998).

\section{RESULTS}

\section{Molecular screening}

PCR amplification with KAM 4 primer gave rise to products of $300 \mathrm{bp}$ only with WRAC 02, WRAC 04, WRAC 07, WRAC 21, WRAC 25 and Ptb 33 (Figure 1) indicating the presence of resistance gene bph2 in their genomes.

\section{Damage scores obtained by test accessions/varieties}

Bioassay by conventional seed box screening test revealed low damage scores with $O$. nivara accessions (score: $2-3$ ) and Ptb 33 (score: 2.5 ) that showed positive results for KAM 04 primer. This indicates the presence of high level of resistance to $\mathrm{BPH}$ in $O$. nivara accessions harbouring bph2, which is similar to that of Ptb 33 (Figure 2).

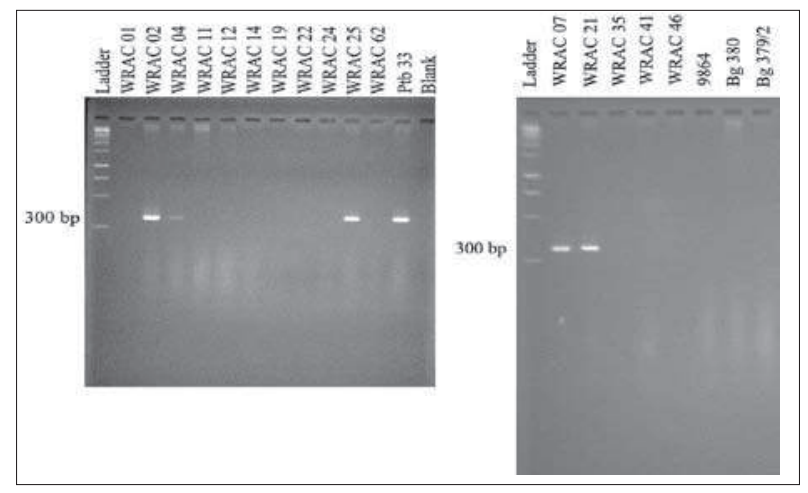

Figure 1: PCR amplification of DNA of the tested rice entries by KAM 4 primer followed by electrophoresis in $3 \%$ agarose gel

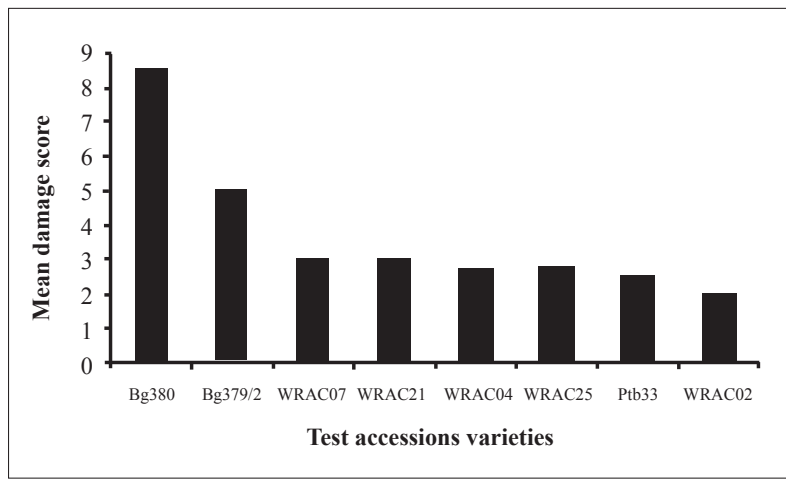

Figure 2: Variation of mean damage scores of test accessions caused by $\mathrm{BPH}$

\section{Antixenosis of $O$. nivara accessions to BPH nymphs} and oviposition

Under free choice conditions, the settling response of BPH nymphs on test accessions and varieties was 
significantly different $(\alpha=0.05)$. The numbers of BPH nymphs observed on Ptb 33 and $O$. nivara accessions were significantly lower than on $\mathrm{Bg} 380$, the highly susceptible variety to the $\mathrm{BPH}$. Also, the mean number of BPH nymphs observed on $\mathrm{Bg} 380$ and $\mathrm{Bg}$ 379/2 significantly increased with time. However, a significant difference of insect numbers on $O$. nivara accessions was not visible during the experiment period (Table 3). These results indicate that all $O$. nivara accessions including Ptb 33 that possess the bph2 gene in their genome have antixenotic characteristics that deter or reduce the BPH nymphs colonizing on them.

Table 3: Antixenosis of BPH nymphs to settle on test accessions

\begin{tabular}{|c|c|c|c|c|}
\hline \multirow[t]{2}{*}{$\begin{array}{l}\text { Test accession / } \\
\text { variety }\end{array}$} & \multicolumn{4}{|c|}{$\begin{array}{l}\text { Mean no. of nymphs/seedling after different times of infestation } \\
\qquad( \pm \text { SD })\end{array}$} \\
\hline & $12 \mathrm{~h}$ & $24 \mathrm{~h}$ & $48 \mathrm{~h}$ & $72 \mathrm{~h}$ \\
\hline WRAC 02 & $2.5( \pm 0.58)^{\mathrm{b}}$ & $4( \pm 0)^{b}$ & $3.25( \pm 0.96)^{b c}$ & $4.5( \pm 0.58)^{\mathrm{c}}$ \\
\hline WRAC 04 & $1.5( \pm 0.58)^{b}$ & $1.5( \pm 0.58)^{\mathrm{e}}$ & $2.25( \pm 0.5)^{\mathrm{cd}}$ & $2.5( \pm 0.58)^{\mathrm{d}}$ \\
\hline WRAC 07 & $2.25( \pm 0.96)^{b}$ & $1.5( \pm 0.58)^{\mathrm{e}}$ & $1.5( \pm 0.58)^{\mathrm{d}}$ & $1.5( \pm 0.58)^{\mathrm{e}}$ \\
\hline WRAC 21 & $2( \pm 1.15)^{b}$ & $2.5( \pm 0.58)^{d}$ & $3( \pm 0)^{\mathrm{bc}}$ & $2.5( \pm 0.58)^{\mathrm{d}}$ \\
\hline WRAC 25 & $2.25( \pm 0.5)^{b}$ & $3.25( \pm 0.5)^{\mathrm{c}}$ & $2.25( \pm 0.5)^{\mathrm{cd}}$ & $1.25( \pm 0.5)^{\mathrm{e}}$ \\
\hline Ptb 33 & $1.75( \pm 0.5)^{b}$ & $2.5( \pm 0.58)^{d}$ & $2.5( \pm 0.58)^{\mathrm{cd}}$ & $2.5( \pm 0.58)^{d}$ \\
\hline Bg 379/2 & $2.5( \pm 0.58)^{b}$ & $3( \pm 0)^{\mathrm{cd}}$ & $4( \pm 0)^{b}$ & $6.5( \pm 0.58)^{b}$ \\
\hline Bg 380 & $9.5( \pm 0.58)^{\mathrm{a}}$ & $11( \pm 0)^{\mathrm{a}}$ & $12.5( \pm 1.73)^{\mathrm{a}}$ & $14.5( \pm 0.58)^{\mathrm{a}}$ \\
\hline
\end{tabular}

Note: Means with same letter of the same column are not significantly different at $5 \%$ level of significance (DMRT).

Under free choice conditions, the number of eggs laid by $\mathrm{BPH}$ in six different test plants was significantly different in each arrangement $(p<0.05)$. The presence of a large number of eggs in the stem is an indication of susceptibility as BPH causes considerable damage to rice plants, not only by feeding but also due to excessive oviposition. In all arrangements, significantly higher and average number of eggs were identified in stems of $\mathrm{Bg} 380$ (variety highly susceptible to the $\mathrm{BPH}$ ) and Bg 379/2 (variety moderately resistant to the BPH), respectively, which was indicative of their level of susceptibility for egg laying over $O$. nivara accessions except WRAC 22 and WRAC 25. In contrast, the least number of eggs were detected in the stems of Ptb 33, WRAC 04, WRAC 02, WRAC 01 and WRAC 35 indicating low preference for egg laying than in the others (Figure 3-A, B, C \& D). However, the number of eggs observed in $O$. nivara accessions harbouring the bph2 gene was significantly lower with the exception of WRAC 25, which showed a difference in antixenosis action against BPH females (Figure 3-B).

\section{Effects on honeydew production of adult BPH females}

Honeydew production of $\mathrm{BPH}$ females on $\mathrm{Bg} 380$ was significantly higher than all the other test accessions and varieties. Bg 379/2, the variety moderately resistant to the BPH produced moderate amounts of honeydew, which was significantly higher than the honeydew production in all $O$. nivara accessions tested. There was also a significant variability of honeydew produced on $O$. nivara accessions (Table 4). These results indicate that $O$. nivara accessions WRAC 21 and WRAC 02 had significant negative effects on feeding behaviour of BPH females over other test accessions with the bph2 gene in their genomes.

\section{Effects on survival of nymphs}

There was a significant difference in survival rates from the first instar nymphs to adults among test accessions and varieties $(p<0.05)$. Significantly higher survival 


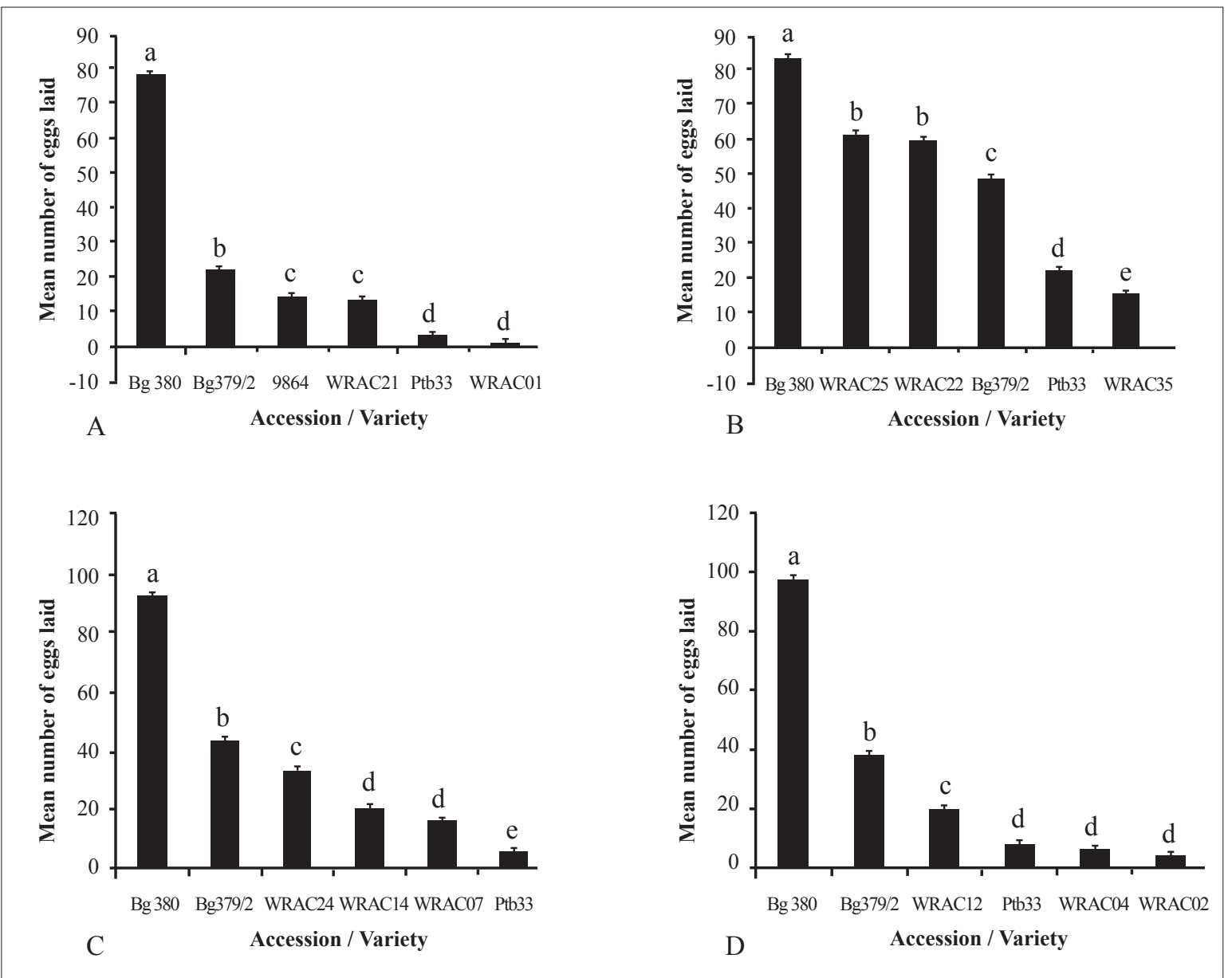

Figure 3: Mean number of eggs laid by BPH in test accessions; different graphs are used to represent the number of eggs laid by BPH females under different arrangements. (A) $1^{\text {st }}$ arrangement; (B) $2^{\text {nd }}$ arrangement; (C) $3^{\text {rd }}$ arrangement; (D) $4^{\text {th }}$ arrangement. Error bars indicate standard errors. Bars labeled with the same letter are not significantly different at $5 \%$ level of significance (DMRT).

Table 4: Honeydew production of BPH females on different test plants

\begin{tabular}{cc}
\hline Accession / variety & Mean spot area $\left(\mathbf{m m}^{2}\right)( \pm$ SD) \\
\hline $\operatorname{Bg~380}$ & $395.5( \pm 5.26) \mathrm{a}$ \\
$\operatorname{Bg~379/2}$ & $121( \pm 2.58) \mathrm{b}$ \\
WRAC 07 & $58.5( \pm 2.52) \mathrm{c}$ \\
WRAC 04 & $50.25( \pm 1.26) \mathrm{d}$ \\
WRAC 25 & $27.25( \pm 2.22) \mathrm{e}$ \\
Ptb 33 & $11.5( \pm 1.91) \mathrm{f}$ \\
WRAC 02 & $2.5( \pm 1.8) \mathrm{g}$ \\
WRAC 21 & $1.25( \pm 1.5) \mathrm{g}$ \\
\hline
\end{tabular}

Note: Means with the same letter are not significantly different at $5 \%$ level of significance (DMRT).

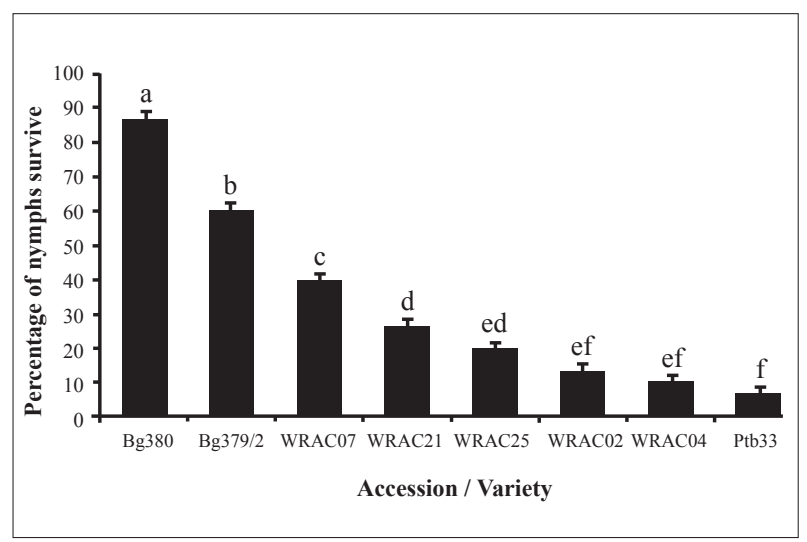

Figure 4: Survival of BPH nymphs fed on different test accessions. Error bars indicate standard errors. Bars labeled with the same letter are not significantly different at $5 \%$ level of significance (DMRT). 
rate $(87 \%)$ was observed in $\mathrm{Bg} 380$, while over $50 \%$ of adult emergence was observed in BPH nymphs fed on $\mathrm{Bg}$ 379/2 as an indication of their level of susceptibility. Among the tested $O$. nivara accessions, WRAC 04 and WRAC 02 showed the least adult emergence, which was not significantly different from that of Ptb 33 . However, a significant variation was found in $\mathrm{BPH}$ nymphs that survive on $O$. nivara accessions harbouring the bph2 gene with WRAC 07 that showed a significantly higher survival rate (40\%) than in the others (Figure 4).

\section{DISCUSSION AND CONCLUSION}

Out of the seventeen $O$. nivara accessions tested, molecular screening revealed positive results with WRAC 02, WRAC 04, WRAC 07, WRAC 21 and WRAC 25 accessions indicating the existence of bph2 gene in their genomes. This work also confirmed the presence of the bph2 gene in the genome of $O$. nivara accession WRAC 04 as the key cause for the resistance (Madurangi et al., 2011). As previously reported (Madurangi et al., 2011), the variety Bg 379/2 developed by RRDI, Bathalagoda using Ptb 33 as a source of resistance failed to confirm the presence of the bph2 gene in its genome.

Bioassay with conventional seed box screening test revealed that $O$. nivara accessions harbouring the bph2 gene survived after BPH infestation at the seedling stage showing high resistance to the $\mathrm{BPH}$. The results of antixenosis and antibiosis effects examined in this study revealed that all $O$. nivara accessions possessing the bph2 gene had substantial levels of antixenosis and antibiosis effects on $\mathrm{BPH}$.

Low honeydew excretion by BPH females and low percentage survival of BPH nymphs indicated the existence of an antibiosis as the mechanism of BPH resistance in $O$. nivara accessions possessing the bph2 gene. It is possible that these accessions lack essential nutrients, which are required for insect survival. Alternatively, these accessions may possess mechanisms or factors, which prevent ingestion of the required quantity of nutrients from a given plant. Also, the reluctance to settle on $O$. nivara and the low number of eggs detected in the stems indicate either the presence of a repellent or the lack of necessary attractant for orientation on the plant.

The observed variations in antixenosis and antibiosis effects of $O$. nivara accessions that possess the bph2 gene may indicate the dynamic response mechanisms of BPH against $O$. nivara and the complex structure of genetics of the resistance of these accessions, which are still unknown. Also, substantial levels of resistance, antixenosis and antibiosis effects observed in $O$. nivara accessions WRAC 02 and WRAC 04, which are similar to Ptb 33 provide a clue to the existence of polygenic resistance in these accessions as detected in Ptb 33 (Khush, 1979). Hence, the results of this study indicated the possible use of $O$. nivara accessions harbouring the bph2 gene as a potential source of resistance and its possible use in pyramiding of genes for $\mathrm{BPH}$ resistance to avoid the genetic uniformity of BPH resistance in rice varieties cultivated in Sri Lanka in the future.

\section{REFERENCES}

1. Alarn S.N. \& Cohen M.B. (1998). Detection and analysis of QTLs for resistance to brown planthopper, Nilaparvata lugens, in a double-haploid rice population. Theoretical and Applied Genetics 9:1370-1379.

2. Anushka K., Kottearachci N.S. \& Attanayake D.P.S.T.G. (2008). Identification of fragrance gene (fgr) in Sri Lankan rice varieties using polymerase chain reaction based molecular markers. Proceedings of $8^{\text {th }}$ Agricultural Research Symposium, 15-16 August. Wayamba University of Sri Lanka. pp. $182-187$.

3. Athwal D.S., Pathak M.D., Bacalangco E. \& Pura C.D. (1971). Genetics of resistance to brown planthoppers and green leaf hoppers in Oryza sativa L. Crop Science 11: 747-750.

4. Cohen M.B., Alam S.N., Medina E.B. \& Bernal C.C. (1997). Brown planthopper, Nilaparvata lugens, resistance in rice cultivar IR 64: Mechanism and role in successful $N$. lugens management in Central Luzon, Philippines. Entomologia Experimentalis et Applicata 85: 221-229.

5. Heinrichs E.A., Medrano F.G. \& Rapusas H.R. (1985). Genetic evaluation for insect resistance in rice, pp. 45-173. International Rice Research Institute, Los Banos, Laguna, The Philippines.

6. Hemachandra P.V., Nawarathne N.M.N., Dissanayake D.W.A.J. \& Geethica W.U.S. (2010a). Morphological characterization of wild rice accessions collected from Sri Lanka. Conservation and utilization of crop wild relatives of Sri Lanka. Book of Abstracts (eds. B. Marambe \& A. Wijesekara), 3 - 4 September. Department of Agriculture and Ministry of Environment and Natural Resources, Sri Lanka. pp.13.

7. Hemachandra P.V., Nawarathne N.M.N., Dissanayake D.W.A.J. \& Geethica W.U.S. (2010b). Wide hybridization studies between cultivated rice (Oryza sativa) and wild rice (Oryza nivara). Conservation and utilization of crop wild relatives of Sri Lanka. Book of Abstracts (eds. B. Marambe \& A. Wijesekara), 3 - 4 September. Department of Agriculture and Ministry of Environment and Natural Resources, Sri Lanka. pp. 21- 22.

8. Hirabayashi H., Angeles E.R., Kaji R., Ogawa T., Brar D.S. \& Khush G.S. (1998). Identification of brown planthopper resistance gene derived from $O$. officinalis using molecular markers in rice. Breeding Science (Suppl.) 48(1): 82. 
9. Ishii T., Brar D.S., Multani D.S. \& Khush G.S. (1994). Molecular tagging of genes for brown planthopper resistance and earliness introgressed from Oryza australiensis into cultivated rice, O.sativa. Genome 37(2): 217 - 221.

10. Jung J.K. \& Im D.J. (2005). Feeding inhibition of the brown planthopper, Nilaparvata lugens (Homoptera: Delphasidae) on a resistant variety. Journal of Asia-Pacific Entomology 8: 301-308.

11. Khush G.S. (1979). Genetics of and breeding for resistance to the brown planthopper. Brown planthopper: Threat to rice production in Asia. Proceedings of the international Conference on Brown planthopper, Los Banos, Laguna, 16 -19 November. International Rice Research Institute, Los Banos, Laguna, The Philippines, pp. $321-332$.

12. Kudagamage C. \& Nugaliyadda L. (1982). Laboratory and field investigations of Brown planthopper (Nilaparvata lugens Stal) resistance in rice varieties. Tropical Agriculturist 138: $149-157$.

13. Kudagamage C. \& Nugaliyadde L. (1995). Present status and future direction of insect pest management in rice. Proceedings of the Rice congress 1990 (eds. S.L. Amarasiri, K. Nagaraj \& B.M.K. Perera), Kandy, 3 - 4 September. Department of Agriculture, Peradeniya, pp. 39 -50.

14. Ling K.C., Tiongco E.R. \& Aguiero V.M. (1978). Rice ragged stunt: a new virus disease. Plant Disease Reporter 62: 701-705.

15. Liu G.Q., Yan H.H., Fu Q., Qian Q., Zhang Z.T., Zhai W.X. \& Zhu L.H. (2001). Mapping of a new gene for brown planthopper resistance in cultivated rice introgressed from Oryza eichingeri. Chinese Science Bulletin 46: 1459 -1462 .

16. Madurangi S.A.P., Samarasinghe W.L.G., Senanayake S.G.J.N., Hemachandra P.V. \& Ratnasekara D. (2011). Resistance of Oryza nivara and Oryza eichingeri derived lines to Brown planthopper, Nilaparvata lugens (Stal) in Sri Lanka. Journal of National Science Foundation of Sri Lanka 39(2): 175-181.

17. Murai H., Hashimoto Z., Sharma P.N., Shimizu T., Murata K., Takumi S., Muri N., Kawasaki S. \& Nakamura C. (2001). Construction of a high resolution linkage map of a rice brown planthopper (Nilaparvata lugens Stal) resistance gene bph2. Theoretical and Applied Genetics 103:526-532.

18. Murata K., Fuguwara M., Murai H., Takumi S., Mori N. \& Nakamura C. (1998). RFLP mapping of a brown planthopper (Nilaparvata lugens Stal) resistance gene $b p h 2$ of indica rice introgressed into a japonica breeding line "Norin-PL4". Genes Genetics Systems 73:359 -364.

19. Pathak M.D., Cheng C.H. \& Fortuno M.E. (1969). Resistance to Nephotettix impicticeps and Nilaparvata lugens in varieties of rice. Nature 223: 502-504.

20. Pathak M.D. \& Kush G.S. (1979). Studies of varietal resistance in rice to brown planthopper. In: Brown planthopper: Threat to rice production in Asia. Proceedings of the international Conference on Brown planthopper, Los Banos, Laguna, 16 -19 November. International Rice Research Institute, Los Banos, Laguna, The Phillippines, pp. $285-301$.

21. Rahman M.L., Jiang W., Chu S.H., Qiao Y., Ham T.H., Woo M.K., Lee J., Khanam M.S., Chin J.H., Jeung J.U., Brar D.S., Jena K.K. \& Koh H.J. (2009). High-resolution mapping of two brown planthopper resistance genes, Bph20(t) and Bph21(t), originating from Oryza minuta. Theoretical and Applied Genetics 119: 1237-1246.

22. Rivera C.T., Ou S.H. \& Lida T.T. (1966). Grassy stunt disease of rice and its transmission by Nilaparvata lugens (Stal). Plant Disease Reporter 50: 453 - 456.

23. SAS Institute (1998). SAS/STAT User's Guide, Version 6.12., SAS Institute, North Carolina, USA.

24. Sogawa K. \& Cheng C.H. (1977). Economic thresholds, nature of damage and losses caused by brown planthopper. In: Brown planthopper: Threat to rice production in Asia. Proceedings of the international Conference on Brown planthopper, Los Banos, Laguna, 16 - 19 November. International Rice Research Institute, Los Banos, Laguna, The Philippines, pp. 125 - 142.

25. Yang H.Y., Ren X., Weng Q.M., Zhu L.L. \& He G.C. (2002). Molecular mapping and genetic analysis of a rice brown planthopper (Nilarparvata lugens Stal) resistance gene. Hereditas 136: $39-43$. 